\title{
The Relationship between Alexitymia and Emotional Intelligence
}

\author{
Fataneh Naghavi \\ Faculty of Human Ecology, University Putra Malaysia \\ Serdang 43400, Malaysia \\ E-mail: ahlo_1359@yahoo.com \\ Marof Redzuan (Corresponding author) \\ Faculty of Human Ecology, University Putra Malaysia \\ Serdang 43400, Malaysia \\ E-mail: Marof@putra.upm.edu.my \\ Mariani Mansor \\ Faculty of Human Ecology, University Putra Malaysia \\ Serdang 43400, Malaysia \\ E-mail: mariani@putra.upm.edu.my
}

\begin{abstract}
The article reviews empirical studies which emphasized on the relation between alexitymia and emotional intelligence (EQ). EQ is a set of abilities such as conception, emotion appraisal and expression, emotion management and regulation, and emotion utilization of emotion. As emotional intelligence is acquisitive and of social origin, parents and children thus expose their emotions in an expressive way to one another, either consciously or unconsciously in their interactions. Adolescence's alexithymia overlay emotional intelligence in the field of emotion identification and to some extent, in feelings expression. Alexithymic adolescence cannot express emotions orally due to inability in feelings identification, whereas preliminary emotional abilities have specific importance because skillfulness in appraisal and quick precise expression of emotions brings about suitable compatibility in relation with environment and others. The research showed that emotional intelligence is negatively associated with alexithymia. The article is divided into several sections. The review is started with the definition of alexithymia, and this is followed by a review on the alexithymia, as well as the effects and interaction of emotional intelligence. Then, an overview of the paper is included a demonstration of the influence of alexithymia on emotional intelligence is also given. Finally, according to previous study it is important to realize that alexithymia does not imply a total unawareness of having emotions.
\end{abstract}

Keywords: Emotional intelligence, Emotion management, Alexitymia, Adolescence

\section{Introduction}

Recognition and emotion have always been focused on in philosophy and later in psychological research. One century before the Christ, Pablilius stated: "rule over your feelings and do not let your feelings rule over you". For a very long period of time, emotions were regarded as non-logical modes which were imperfect and confused. Some research even indicates that emotion release is not valuable without recognition processing. Similarly, mental ruminating as to negative emotions causes depression to increase. However, is uncontrolled emotion release and rumination the only ways of using emotions (Schwartz 2000)?

Today, absolute recognition focus in man's psychological studies has been replaced by emotion and recognition influence and role in his/her psychic health and development. Recognizing emotions and feelings is a basis for emotional intelligence. Emotional intelligence is conceptualized to incorporate recognition and emotion or intellectual emotion. Although psychological systems have negatively looked into emotions, the attention given to emotions and feelings can be regarded as the core and basis of psychology and one can therefore look for mental disturbances roots in emotional perturbations like fear, anxiety, depression and alexithymia. 
Freud (1995) used free association and dream interpretation in his treatments and helped patients restate their thoughts and desires by providing an ambience free of the judgment and appraisal of wisdom.

This insight towards behaviour is not only intellectual, but also a correcting emotional experience. This new experience is both the change center and the main factor of psychotherapy. The aim of psychoanalysis is emotional reconciliation and insight creation; insight is a method to acquire emotional reconciliation. In the course of psychoanalysis, primary emphasis is on the clarification of emotions and feelings. Similarly, Parker (2010) also emphasizes consciousness in psychoanalysis. Gestalt-therapy techniques are defined by two bahavioural axes, namely "rules" and "designs." In particular, rules are effective instruments to integrate the thought and feeling of references, while designs are activities carried out by references to recognize different poles of their personality and dealing with facts (Kersini, 1996 cited in Shafiabadi and Naseri, 1998).

Considering the potential influences on emotional intelligence and alexithymia may be useful and vital. If numerous factors are found to influence emotional intelligence, then individuals can find ways to enhance emotional intelligence and subsequent lifelong achievement. This process is undoubtedly one of the importance ways that lad to individual and social development.

Among the pioneers of family treatment, Virginia Stair was one who had placed the highest emphasis on feelings in the family. In the same vein, she paid attention on the family's daily work and emotional experiences. At the same time, she also persuaded family members to describe their feelings and notice both facial and non-verbal states of one another (Stair and Baldwin, 1983).

Considering the above information, it seems that one of the aims of psychology, consultation, and psychoanalysis is the development of patients' emotional intelligence. Considering the orientation of the recent studies in the identification and role of emotional intelligence, as a concept different from personality and emotional quotient (EQ), a clear and comprehensive recognition of this structure is therefore achieved when the family's role in development and its relation with emotional intelligence is specified.

Alexithymia overlays emotional intelligence in the field of emotion identification and to some extent, in feelings expression. An alexithymic adolescence cannot express his/her emotions orally due to inability in feelings identification, whereas preliminary emotional abilities have specific importance because skillfulness in appraisal and quick precise expression of emotions brings about suitable compatibility in relation with environment and others (Taylor and Bagby, 2002).

\section{What is Alexitymia?}

Alexithymia is considered to be a personality trait that places individuals at risk for other medical and psychiatric disorders while reducing the likelihood that these individuals will respond to conventional treatments for the other conditions (Havilland et al., 2000) Alexithymia is not classified as a mental disorder in the DSM-IV. It is a dimensional personality trait that varies in severity from person to person. A person's alexithymia score can be measured with questionnaires such as the Toronto Alexithymia Scale (TAS-20), the Bermond-Vorst Alexithymia Questionnaire (BVAQ), (Vorst and Bermond, 2001) or the Observer Alexithymia Scale (OAS) (Havilland et al., 2000)

According (Taylor et al., 1990) Hence, Alexithymia in the context of this study is defining as:

1. Difficulty identifying feelings and distinguishing between feelings and the bodily sensations of emotional arousal

2. Difficulty describing feelings to other people

3. Constricted imaginably processes, as evidenced by a paucity of fantasies

4. A stimulus-bound, externally oriented cognitive style.

\section{History and Meaning of Emotional Intelligence}

Emotion is resulted from interaction between physiological stimulation and appraisal of situation identification. When there is physiological stimulation, it is the stimuli, conditions, and signs surrounding the individual that specify which emotional state he/she will experience. Emotions are functional and social, and emotional experiences inside us to others through creating distinctive facial and body states (Marshal, 1997). Mayer and Salovey (1997) indicate that emotional intelligence is the ability to percept precisely, appraise and express emotions of one's own and others' access and generate feelings when they facilitate thinking, as well as regulate and utilize emotions in problem solving(Saarni, 2000). 
The history of research on intelligence has made it clear that the reason for people's success in their personal and occupational life is not merely EQ. Years before that, Throndike (1920) presented a model of intelligence which included not only the factors of traditional intelligence, but also the factor that he called as 'social intelligence'. He defined it as the ability to understand and management of wise action and behaviour in human relations. Throndike's definition of social intelligence was a behavioural and cognitive ability and it implied that firstly, man's conception and management abilities are intellectual abilities, and secondly, such abilities are distinct from the classic, abstract, and mechanical-objective aspects of intelligence. Since then, much attention has been paid on the concept of social intelligence. For years, the principal question has been that whether an empirically unique and solid limit for social intelligence can be specified, and whether it is only a function of a more general abstract intelligence. A lot of studies have been carried out to separate educational-scientific intelligence from social intelligence, but only a little progress has been made (Brown and Antony, 1990; Ford and Tisak, 1983). According to Ford and Tisak (1983) most of such studies were not successful due to two reasons; first, defining social intelligence is difficult a different task and different researchers have presented different definitions, whereas other definitions consider it a multi-dimensional structure. The second problem lies in the method to be used to measure social intelligence so that it is justifiable from psychometric point of view.

Considering such problems in relation to the concept of social intelligence, analyses tended to use other conceptualization and non-intellectual factors measurement methods. Another option was the concept of emotional intelligence which was introduced by Mayer and Salovey (1990) and later developed by Goleman (1998). This concept originated form Waksler's general non-intellective factors thought (1940, 1942). Later, Leeper (1948) applied this concept and assumed that emotional thoughts were a part of logical intelligence and played a role in logical and general intelligence. For about forty years, nothing else was done regarding emotional intelligence until Gardner (1983) introduced his Multiple Intelligence theory, which incorporating the cognitive aspects of intelligence. Both the cognitive and emotional aspects of intelligence are incorporated in Gardner's theory. This theory includes seven independent kinds of intelligence; one is personal intelligence that is divided into intrapersonal intelligence - knowledge of one's internal feelings and events, and interpersonal intelligence - the ability to specify others' reactions, needs, emotions, and purposes (Derksens, Kramer and Katzko 2002).

Emotional intelligence is a form of social intelligence (Salovey and Mayer, 1990) and a suitable predictor of general functioning and particular areas such as occupational performance (Goleman, 1995; 1998), including one's ability to manage his/her and others' feelings and emotions, distinguish between them, and use such information to direct one's thinking and practice (Salovey and Mayer, 1990). Moreover, emotional intelligence, also, has the scientific features of a rational intelligence (Mayer, Salovey, Karoso, 2002), as elaborated:

(1) Conceptual criterion: emotional intelligence reflects mental functioning, not the salient methods of behaving or sagacity-free skills, or self-respect only. In other words, it measures abilities related to emotion (Carole, 1993; Mayer and Salovey; 1993).

(2) Correlation criterion: emotional intelligence includes a set of abilities which are dependant and related to other mental skills, described by other kinds of proved intelligence (Carole, 1993).

(3) Developmental criterion: emotional intelligence develops along with age and experience from childhood to adulthood (Brown 1997, Fancher 1985). Considering the evolutional aspects of emotional intelligence, three mental abilities of adolescents are significant; namely (a) conception, appraisal, and expression of emotion, (i.e. the ability to identify and understand one's and others' emotions based on situational and expressional cues, emotional meanings of which are in accordance with culture); (b) emotions regulation and management and one's ability to compatibly dealing with opposite or negative emotions using self-regulation methods that improve the extent or duration of such emotions, the ability to create joyful conditions for others, as well as concealing one's negative emotions to avoid harming others' personal feelings (Sarni, 1999); (c) emotion utilization, i.e. the ability to plan flexibly and use emotions in problem-solving (Salovey and Mayer, 1990).

\section{Alexitymia and Emotion Intelligence}

A 20-year research on interactions between emotion and cognition has created a basis for the recent works on emotional intelligence. The concept of emotional intelligence, which was first introduced by Salovey and Mayer in 1990, is a strong basis to study individual differences, particularly on how reasoning is done by feelings and about feelings. A recently developed orientation has shifted its focus from emotional intelligence concept as a property or trait (i.e. Bar-on, 1977; Schutte et al., 1998) to conceptualization of capabilities in emotional intelligence (Salovey and Caruso, 2000; Sitarenios, 2001). According to this orientation, emotional intelligence is one's ability to comprehend, express, understand, apply, and manage emotions in oneself and others (Kafetsios 2003). Considering the developmental aspects of emotional intelligence, three features of mental capabilities in 
adolescents take special importance; these are (1) comprehension, appraisal and emotion expression, (2) emotion regulation and management, (3) emotion utilization (Saarni, 1999). Children learn to express, comprehend, understand, and regulate emotions by exchanging their emotions with parents and coevals. Some of them take control of their own and others' emotions more skillfully due to big differences in individual abilities and their social world. On the other hand, some children lack adequate skills to interpret emotions for achievement in the social world (Scharfe, 2000).

It is important to realize that alexithymia does not imply a total unawareness of having emotions. Adolescence with alexithymic characteristics may, for example, complain of depression. The emotions of alexithymic individuals, however, are relatively diffuse, poorly differentiated and not well represented psychically. Furthermore, a tendency to an externally oriented and unimaginative way of thinking does not mean that people with high levels of alexitymia are totally incapable of imagining but, rather, that the contents of their mental imagery are mundane and focused on everyday tasks.

Meanwhile, more recent findings indicate that appropriate emotional raise of children is an important factor which affects their future achievements in different fields (Goleman 1998). Emotional intelligence enables an individual to correctly exhibit suitable amount of different emotions such as rage, fear, love, happiness, etc. in his/her bahaviour proportional to the situations and time. Moreover, it enables them to know about others' emotions and react accordingly (Goleman, 1998; Mayer, Salovey, Caruso, 2000).

Adolescence is a sensitive period of one's life when he/she begins investigating their surroundings and seeks to establish relationship with. Adolescents' relations with their parents become deranged and they should take some distance from sisters and brothers sub-system, and find responsibilities and independence proportional to their age. Thus, parental sub-system relationship with them should change from parents-child to parents-young adult mode (minuchin, 2005). An important task during growth for children and adolescents is therefore to learn expression or instrument, recognize and comprehend emotional states accurately. This is particularly because they benefit from emotional knowledge as a guide in the social world (Scharfe, 2000).

In adolescence period, feelings and emotions conduct individuals in the course of life, so the adolescent's attention and tendency to things outside of home and conflicts between them and their parents in this period provide the ground for the influences inflicted by social damages. If the family fulfils its roles and tasks correctly and enjoys required efficiency, it can protect its members against external damages. On the contrary, emotional intelligence can help adolescents to identify emotions and shocks so that they can correctly appraise, understand, express, and use emotions in their thinking and practice. Therefore, emotional intelligence is a protecting factor against social damages, and based on relevant research, it is also associated with successful marriage, life satisfaction, as well as job and academic achievements (Goleman, 1998; Trinided and Johnson, 2002; Palmer, Donaldson and Stough, 2002; Karsini , Mayer and Warner, 2003).

Although difficulty in monitoring the feelings and emotions of other people is not part of the definition, empirical studies have shown that individuals with high degrees of alexithymia experience difficulties in accurately identifying emotions in the facial expressions of others (Lane et al., 1996; Parker, Taylor \& Bagby, 1993).

\section{Conclusion}

Based on the literature review, it can therefore be concluded that emotional intelligence has been put forward for about two decades and many related studies have been carried out to study it. It is understood from the previous studies that emotional intelligence is associated with factors such as life satisfaction, adaptability, optimism, overall intelligence, personality, and emotional disorders like alexithymia, depression, and anxiety. Previous studies have also shown that girls are higher than boys in their emotional intelligence, but high emotional intelligence in boys is a better predictor for achievement. Research orientation has mostly been done toward clarifying and expanding the concept of emotional intelligence. Thus, according to these studies person with alexithymia, a severe state of low emotional intelligence lacks the verbal ability to express emotion or to describe emotions in others.

\section{References}

Bar-on, R. (1977). Emotional and social intelligence: Insights from the emotional quotient inventory. The Handbook of Emotional Intelligence, 23, 490-504.

Brown, M. (1997). Quality of emotional intelligence. Psychology Journal, 38, 67-71.

Carole G, L. G. (1993). Family Treatment. Efficient Therapy Guarantee, 14, 234-256.

Derksen, J., Kramer, I., \& Katzko, M. (2002). Dose a self-report measure for emotional intelligence assess something different than general intelligence? Personality and Individual Differences, 32, 37-48.

Fancher. (1985). Emotional intelligence abilities across the life course. Personality and Individual Differences, 14, 23-29. 
Ford, B. Tisak. (1983). Care of life. Journal of medicine, 50, 30-71.

Freud, S. (1995). Family therapy. An overview, (4 E).21, 213-237.

Haviland., MG, Warren WL, \& Riggs, ML. (2000). "An observer scale to measure alexithymia". Psychosomatics $41 \quad$ (5): $\quad 385-92 . \quad$ doi:10.1176/appi.psy.41.5.385. PMID 11015624.http://psy.psychiatryonline.org/cgi/content/full/41/5/385 2632.

Goleman, D. (1998). Working with emotional intelligence. Psychosomatic Medicine, 10, 24-29.

Goleman, D. (1995). Emotional Intelligence. Psychosomatic Medicine, 8, 160-168.

Kafetsios, K. (2003). Attachment and emotional intelligence abilities across the life course. Personality and Individual Differences. London: Sage.

Karsini, H., Allan, W. D., Mayer, J. M., Werner M., Reid, J. C. (2003). An examination of family functioning utilizing the circumplex model in psychiatrically hospitalized children with depression. Journal of Affective Disorders, 35, 65-73.

Lane, R., Sechrest, L., Reidel, R., Weldon, V., Kaszniak, A., \& Schwartz, G. (1996). Impaired verbal and nonverbal emotion recognition in alexithymia. Psychosomatic Medicine, 58, 203-210.

Leeper, M. A., Mader, C., Gramzow, J., Papineau, K. (1948). Family factors related to alexithymia characteristics. Psychosomatic, 58, 211- 216.

Marshal, G. R. (1997). Stimulation and Emotion. Personality and Individual Differences, 12, 235-243.

Mayer, J. D., Salovey, P. (1993). What is a emotional intelligence? Emotional development and emotional intelligence: Implications for educators. New York: Basic Books.

Mayer, J. D., Salovey, P., Caruso, D. R. (2002). Relation of an ability measure of emotional intelligence to personality. Journal of personality Assessment, 79, 306 -320.

Mayer, J. D., Salovey, P., Caruso, D. R. (2000). Emotional intelligence as zeitgeist, as personality, and as a mental ability. The handbook of emotional intelligence.NJ: Prentice Hall.

Minuchin S., F. H. (2005). Techniques of Family Treatment. Multilingual Matters Limited.

Palmer, F., Donaldson \& Stough. (2002). What is emotional intelligence? Psychology journal 27, 234-256.

Parker, J. D. D. (2010). The handbook of emotional intelligence: Sage Publications.

Parker, J. D. D., Taylor, G. J., \& Bagby, R. M. (2002). Alexithymia and the recognition of facial expressions of emotion. Psychotherapy and Psychosomatics, 59, 197-202.

Saarni, C. (1999). The development of emotional competence. Journal of psychology, 12, 234-245.

Saarni, C. (2000). The handbook of emotional intelligence. Emotional competence: A developmental perspective. Waveland Press.

Sanaei, B. (1991). An Introduction on Systemic View to Family Psychotherapy. Personality and Individual Differences, 34, 707-721.

Schutte, Marfe, D. Bolden, C. (1998). Consultation and Psychotherapy Theories. Rasa Cultural Institute, 23, 34-56.

Scharfe, E. (2000). The handbook of as emotional intelligence. Development of emotional expression, understanding, and regulation in infants and young children. New York, NY: Teacher College Press.

Schwartz, R. C., Johnson, S. M. (2000). Do couple and family therapy have emotional intelligence. Family process, 39, 29-33.

Sitarenios, N. (2001). Family management. Family journal, 50, 47-53.

Stair, V. M., Baldwin, M. (1983). Step by step. Palo Alto. Science and Behavior.CA, 21,98-102.

Taylor, G. J., Bagby, R. M. (2002). The handbook of emotional intelligence. An overview of the alexithymia construct. Waveland Press.

Trinided, H., Johnson. (2002). The handbook of emotional intelligence. Emotional competence: A developmental perspective. San Francisco: Inc.

Vorst, H, CM., Bermond, B. (2001). Validity and reliability of the Bermond-Vorst Alexithymia Questionnaire. Personality and Individual Differences, 30, 413-434.

Walsh, F. (1993). Normal family process. The Guilford Press. 